\title{
Analisa Pengaruh Variasi Pinch Point dan Approach Point terhadap Performa HRSG Tipe Dual Pressure
}

\author{
Ryan Hidayat dan Bambang Arip Dwiyantoro \\ Jurusan Teknik Mesin, Fakultas Teknologi Industri, Institut Teknologi Sepuluh Nopember (ITS) \\ Jl. Arief Rahman Hakim, Surabaya 60111 Indonesia \\ e-mail: bambangads@me.its.ac.id
}

\begin{abstract}
Abstrak-Siklus kombinasi adalah siklus termodinamika yang menggabungkan siklus Rankine dan siklus Brayton dengan komponen HRSG sebagai penghubung. Untuk mendapat rancangan HRSG yang baik, maka perlu untuk mengetahui pengaruh parameter internal maupun eksternal dari HRSG. Parameter yang ditinjau adalah pinch point dan approach point, juga perubahan beban turbin gas. Dengan menggunakan perangkat lunak cycle tempo, simulasi pembangkit dengan konfigurasi 1x1x1 dilakukan. Hasil yang didapat dari simulasi adalah nilai net power output, net plant efficiency, dan net plant heat rate dengan variasi parameter yang telah disebutkan. Setelah simulasi dilakukan, pada beban turbin gas $100 \%$ didapatkan hasil berupa nilai net power output sebesar $\mathbf{7 2 , 2 0 5} \mathrm{MW}$ yang mengalami penurunan, juga net plant efficiency $47,044 \%$, dan net plant heat rate $7652,3 \mathrm{~kJ} / \mathrm{kWh}$ yang tetap seiring menurunnya beban turbin. Sementara untuk variasi pinch point dan approach point akan mengakibatkan power output, dan net plant efficiency meningkat, dan net plant heat rate menurun seiring dengan berkurangnya nilai kedua parameter tersebut. Variasi yang menghasilkan performa terbaik adalah pada pengurangan nilai pinch point modul low pressure dimana pinch point sebesar $50,8^{\circ} \mathrm{C}$ dan approach point $9,77^{\circ} \mathrm{C}$ menghasilkan power sebesar $16,069 \mathrm{MW}$, net plant efficiency sebesar $50,462 \%$, dan net plant heat rate sebesar $7132,535 \mathrm{~kJ} / \mathrm{kWh}$, namun untuk dapat membangkitkan daya sebesar itu diperlukan tambahan sumber panas sebesar $25 \mathrm{MW}$.
\end{abstract}

Kata Kunci-approach point, cycle tempo, HRSG, pinch point

\section{PENDAHULUAN}

$\mathrm{S}$ IKLUS kombinasi adalah salah satu jenis siklus termodinamika yang memiliki fungsi sebagai pembangkit daya. Siklus kombinasi sendiri merupakan gabungan dari siklus Rankine dan siklus Brayton [1]. Siklus Rankine dengan fluida kerja berupa air, dan siklus Brayton dengan fluida kerja gas, dapat digabung menjadi siklus kombinasi dengan komponen heat recovery steam generator (HRSG). Prinsip dari siklus kombinasi sendiri adalah dengan memanfaatkan panas yang tinggi yang dimiliki oleh gas buang turbin gas dalam siklus Brayton sebagai sumber panas yang berfungsi untuk membangkitkan uap air dalam siklus Rankine. Pada HRSG sendiri, terdapat banyak parameter yang dapat dijadikan acuan untuk perancangannya, salah satunya adalah pinch point dan approach point [2]. Selain itu, juga menarik untuk diketahui bagaimana kinerja HRSG ketika dioperasikan turbin gas dengan beban yang berbeda.

Untuk membantu penelitian, digunakan bantuan perangkat lunak cycle tempo. Dalam cycle tempo, kita dapat melakukan perancangan pembangkit seperti apa yang kita kehendaki. Sebagai data acuan maka digunakan pembangkit siklus kombinasi dengan konfigurasi 1x1x1 (1 turbin gas - 1 HRSG tekanan dua tingkat -1 turbin uap tekanan tunggal). Setelah dilakukan simulasi, akan dibandingkan bagaimana performa dari HRSG dengan melakukan variasi beberapa parameter yang sudah ditentukan, yaitu beban turbin gas, pinch point, dan approach point. Dan yang akan menjadi tolak ukur adalah nilai net power output, net plant efficiency, dan net plant heat rate yang dapat dihasilkan dari pemodelan pembangkit tersebut.

Penelitian untuk mengetahui pengaruh parameter desain terhadap performa HRSG sudah cukup banyak dilakukan sebelumnya. Seperti Achsan Arfandi yang melakukan penelitian pengaruh pinch point terhadap siklus kombinasi dengan konfigurasi $2 \times 2 \times 1$, dimana dapat diketahui dengan meningkatnya pinch point maka akan didapatkan daya yang lebih menurun dari pembangki [3]. Dan Ragland, Stenzel yang melakukan penelitian pengaruh pinch point dan approach point terhadap HRSG tekanan tiga tingkat, yang dapat disimpulkan bahwa dengan semakin kecil parameter tersebut akan membuat biaya yang dibutuhkan untuk membangun pembangkit menjadi lebih besar [4]. Juga dengan mengadaptasi penelitian Dendi Nugraha yang mencoba mengamati pengaruh perubahan komponen sirip pada pipa terhadap performa kolektor surya [5]. Namun belum ada yang melakukan penelitian untuk menganalisa HRSG tekanan dua tingkat dalam konfigurasi 1x1x1, yang mana uap pada tekanan rendah digunakan sebagai suplai deaerator dan suplai untuk turbin uap digunakan dari uap tekanan tinggi. Oleh karena itu, dilakukan penelitian ini untuk mengetahui pengaruh dari parameter tersebut terhadap performa HRSG.

\section{METODE PENELITIAN}

Analisa dalam penelitian ini meliputi analisa performa pembangkit, analisa pinch point dan approach point, dan simulasi pada cycle tempo.

\section{A. Analisa Performa Pembangkit}

Dalam penelitian ini, akan dipelajari bagaimana karakteristik perubahan parameter pada HRSG serta dampaknya terhadap performa yang dihasilkan permbangkit secara keseluruhan. Untuk itu, diperlukan data heat balance yang dimiliki pembangkit sebagai acuan dalam melakukan simulasi pada cycle tempo. Setelah itu, variasi bisa dilakukan pada komponen HRSG agar diketahui karakteristik perubahan parameternya. Input data heat balance pada cycle tempo dapat dilihat pada gambar 1. 


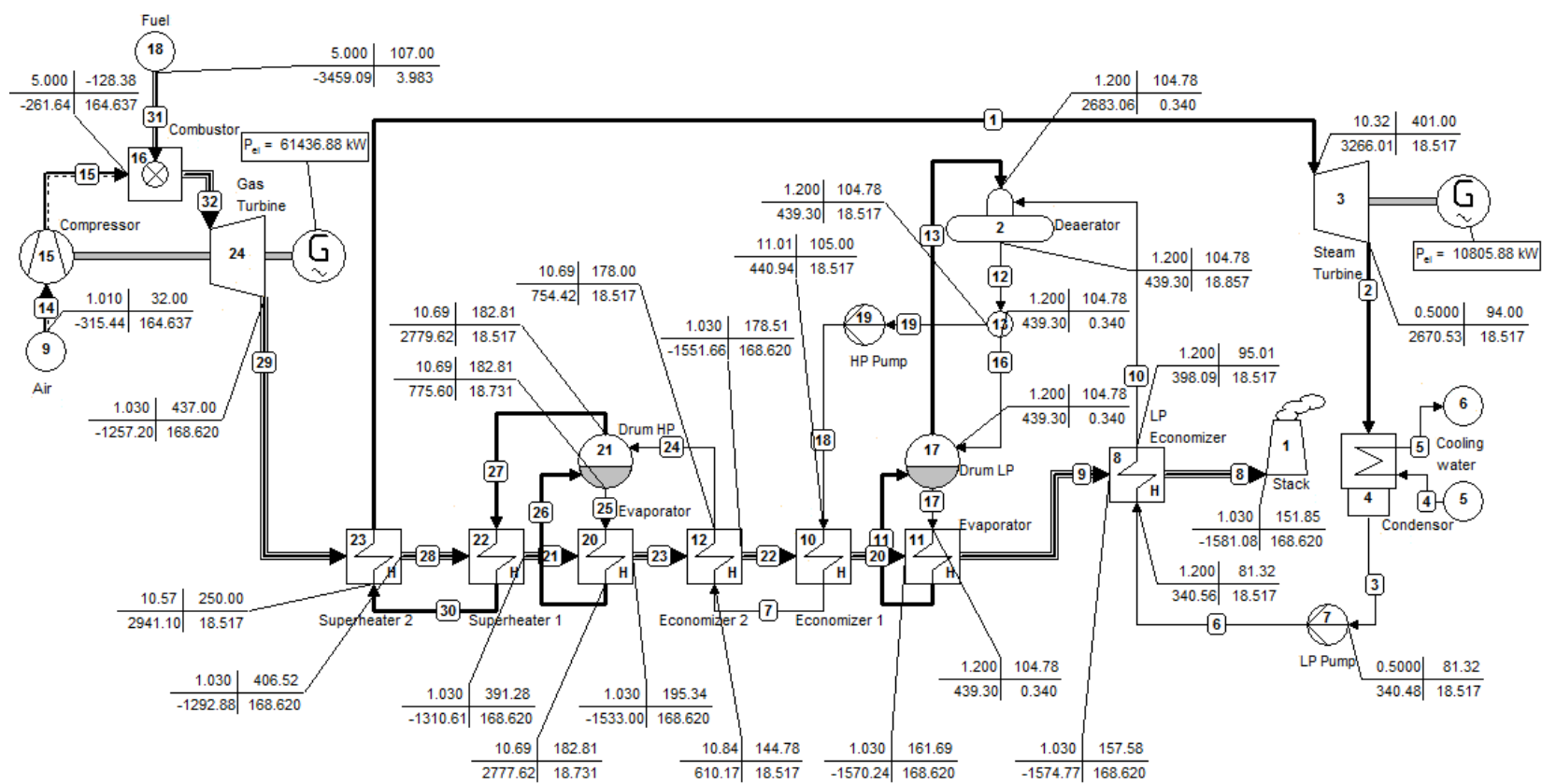

Gambar. 1. Simulasi Pembangkit Konfigurasi 1x1x1

Dalam penelitian, akan ditinjau bagaimana pengaruh HRSG terhadap pada pembangkit. Dan yang akan menjadi tolak ukur adalah nilai net power output, net plant efficiency, dan net plant heat rate yang dapat dihasilkan dari pemodelan pembangkit tersebut.

\section{- Net Power Output}

Untuk net power output yang dimaksud adalah daya yang dapat dihasilkan pembangkit dengan data acuan yang ada. Untuk mencari nilai net power output dapat dilakukan dengan persamaan dibawah:

dengan:

$$
W_{\text {total }}=W_{G T}+W_{S T}-W_{a u x}
$$

$\mathrm{W}_{\text {total }}=$ Net power output $(\mathrm{kW})$

$\mathrm{W}_{\mathrm{ST}} \quad=$ Daya turbin uap $(\mathrm{kW})$

$\mathrm{W}_{\mathrm{GT}} \quad=$ Daya turbin gas $(\mathrm{kW})$

$\mathrm{W}_{\text {aux }}$ = Daya yang dibutuhkan pembangkit, contohnya daya pompa $(\mathrm{kW})$

\section{- Net Plant Efficiency}

Adalah perbandingan antara daya yang dihasilkan dengan kalor yang digunakan. Persamaan net plant efficiency seperti pada persamaan dibawah ini:

dengan:

$$
\eta=\frac{W_{\text {total }}}{Q_{\text {in }}}
$$

$$
\begin{array}{ll}
\eta & =\text { Net plant efficiency }(\%) \\
\mathrm{Q}_{\text {in }} & =\text { Sumber kalor }(\mathrm{kW})
\end{array}
$$

\section{- Net Plant Heat Rate}

Adalah untuk mengetahui berapa kebutuhan kalor untuk dapat menghasilkan $1 \mathrm{kWh}$ dalam pembangkit tersebut. Persamaan net plant heat rate seperti pada persamaan dibawah ini:

Dengan:

$$
\text { Net plant heat rate }=\frac{\left(\dot{m}_{\text {fuel }} \cdot L H V\right)}{W_{\text {total }}}
$$

$\dot{m}_{\text {fuel }}=$ mass flow bahan bakar. input dalam cycle tempo adalah $3,983 \mathrm{~kg} / \mathrm{s}$ kemudian dikonversi untuk waktu 1 jam (3600 s) sehingga menjadi $14.338 \mathrm{~kg} / \mathrm{h}$

$L H V=$ Nilai kalor bawah bahan bakar $(\mathrm{kJ} / \mathrm{kg})$

\section{B. Analisa Pinch Point dan Approach Point pada HRSG}

Dalam penelitian ini, salah satu parameter yang menjadi tinjauan adalah nilai pinch point dan approach point. Pinch point adalah selisih antara temperatur gas keluar evaporator dengan temperatur jenuh air pada evaporator. Sementara approach point adalah selisih antara temperatur air keluar economizer dengan temperatur jenuh air pada evaporator. Penjelasan pinch point dan approach point dapat dilihat pada gambar 2.

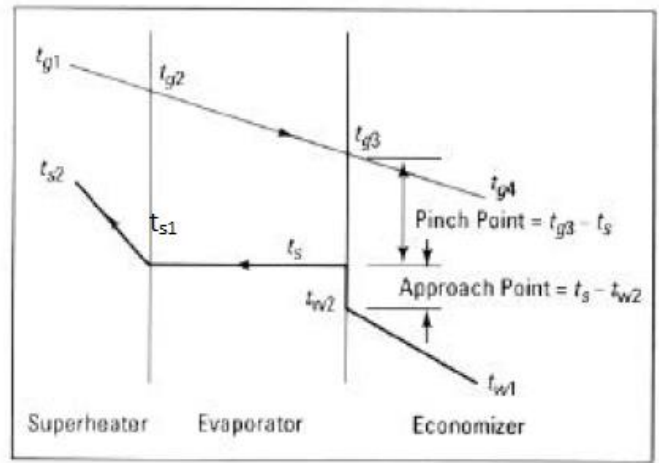

Gambar. 2. Profil diagram temperatur antar gas buang dan uap

- Kesetimbangan energi pada economizer

$$
\dot{m_{\mathrm{s}}}\left(h_{\mathrm{w} 2}-h_{\mathrm{w} 1}\right)=\dot{m_{g}}\left(h_{\mathrm{g} 3}-h_{\mathrm{g} 4}\right)
$$

dengan:

$\dot{m_{\mathrm{s}}}=$ mass flowrate air $(\mathrm{kg} / \mathrm{s})$

$h_{\mathrm{w} 1}=$ enthalpy air masuk economizer $(\mathrm{kJ} / \mathrm{kg})$

$h_{\mathrm{w} 2}=$ enthalpy appraoach temperature point $(\mathrm{kJ} / \mathrm{kg})$

$m_{g}=$ mass flowrate gas buang gas turbine $(\mathrm{kg} / \mathrm{s})$

$h_{\mathrm{g} 4}=$ enthalpy gas buang keluar economizer $(\mathrm{kJ} / \mathrm{kg})$

$h_{\mathrm{g} 3}=$ enthalpy gas buang masuk economizer atau keluar evaporator $(\mathrm{kJ} / \mathrm{kg})$

- Kesetimbangan energi pada evaporator

dengan:

$$
\dot{m_{\mathrm{s}}}\left(h_{\mathrm{s} 1}-h_{\mathrm{w} 2}\right)=\dot{m_{g}}\left(h_{\mathrm{g} 2}-h_{\mathrm{g} 3}\right)
$$

$h_{\mathrm{s} 1}=$ enthalpy uap air keluar evaporator atau masuk superheater $(\mathrm{kJ} / \mathrm{kg})$ 
$h_{\mathrm{g} 2}=$ enthalpy gas buang keluar superheater atau masuk evaporator $(\mathrm{kJ} / \mathrm{kg})$

- Kesetimbangan energi pada superheater

$$
m_{\mathrm{s}}\left(h_{\mathrm{s} 2}-h_{\mathrm{s} 1}\right)=m_{g}\left(h_{\mathrm{g} 1}-h_{\mathrm{g} 2}\right)
$$

dengan:

$h_{\mathrm{s} 2}=$ enthalpy uap air keluar superheater $(\mathrm{kJ} / \mathrm{kg})$

$h_{\mathrm{g} 1}=$ enthalpy gas buang masuk superheater $(\mathrm{kJ} / \mathrm{kg})$

\section{Simulasi pada Cycle Tempo}

Tahap selanjutnya adalah dilakukan pemodelan pada perangkat lunak cycle tempo, berdasarkan data heat balance yang didapat. Hasil simulasi dapat dilihat pada tabel 1 dan pemodelannya pada gambar 1 .

Tabel 1.

Perbandingan Daya output heat balance dan hasil simulasi Cycle tempo

\begin{tabular}{lcc}
\hline \hline \multicolumn{1}{c}{ DATA } & Daya Netto [kW] & Efisiensi Netto [\%] \\
\hline Heat Balance & 71.002 & 46,26 \\
Simulasi Cycle Tempo & 72.205 & 47,044 \\
\hline \hline
\end{tabular}

Jika sudah tidak terdapat error dan warning pada saat running, maka dapat diartikan bahwa hasil yang perhitungan dalam perangkat lunak cycle tempo tersebut sudah konvergen. Setelah itu, dilakukan proses validasi untuk mengetahui apakah hasil yang diberikan simulasi cycle tempo adalah hasil yang valid jika dibandingkan dengan data acuan yang digunakan. Hasil yang valid ditunjukkan dengan nilai error dibawah 5\%, dan untuk simulasi yang sudah dilakukan dapat disimpulkan bahwa data hasil simulasi adalah valid, karena error pada daya netto sebesar 1,69\% dan pada efisiensi sebesar $1,61 \%$.

Setelah berhasil dilakukan simulasi, validasi, dan perhitungan nilai yang dibutuhkan dengan menggunakan data acuan heat balance. Selanjutnya dilakukan variasi dengan dua parameter. Pertama adalah variasi terhadap beban turbin gas, dan yang kedua adalah variasi terhadap nilai pinch point dan approach point.

\section{HASIL DAN DISKUSI}

\section{A. Variasi Beban Turbin Gas}

Untuk variasi pembebanan pada turbin gas, data yang dijadikan sebagai acuan adalah data heat balance. Lalu yang dijadikan sebagai input pada perangkat lunak cycle tempo untuk membedakan kondisi tiap pembebanan adalah laju alir massa bahan bakar dan udara yang menyesuaikan dengan data laju alir massa gas buang turbin gas yang sebelumnya sudah didapatkan pada proses pengumpulan data yang dibutuhkan. Dengan kondisi apparatus yang sama mengikuti beban $100 \%$ turbin sesuai data heat balance.

Berdasarkan tabel 2, hasil simulasi menunjukkan variasi perubahan beban turbin gas hanya mempengaruhi pada nilai power output turbin, namun tidak pada efficiency dan heat rate. Hal itu disebabkan karena pada simulasi ini kondisi komponen pembangkit masih dalam keadaan $100 \%$ beban turbin, sehingga kondisi kalor yang terserap pada HRSG tidak berbeda pada tiap kondisi. Seharusnya apabila akan meninjau pembebanan turbin pada kondisi yang berbeda maka harus memiliki data heat balance keadaan komponen pembangkit di tiap kondisi yang berbeda tersebut. Sehingga data performa akan lebih tepat, khususnya efficiency dan heat rate.

Tabel 2.

Hasil Variasi Beban Turbin Gas

\begin{tabular}{ccccc}
\hline \hline $\begin{array}{c}\text { Gas } \\
\text { Turbine } \\
\text { Load }\end{array}$ & $\begin{array}{c}\text { Exhaust } \\
\text { Flow (kg/s) }\end{array}$ & $\begin{array}{c}\text { Total } \\
\text { Power } \\
(\mathbf{k W})\end{array}$ & $\begin{array}{c}\text { Net } \\
\text { Plant } \\
\text { eff }\end{array}$ & $\begin{array}{c}\text { Net plant } \\
\text { heat rate } \\
(\mathbf{k J} / \mathbf{k W h})\end{array}$ \\
\hline $100 \%$ & 168,62 & 72.205 & $\begin{array}{c}47,044 \\
\%\end{array}$ & $7.652,3$ \\
$90 \%$ & 156,42 & 66.981 & $\begin{array}{c}47.042 \\
\%\end{array}$ & $7.652,4$ \\
$80 \%$ & 145,9 & 62.476 & $\begin{array}{c}47.049 \\
\%\end{array}$ & $7.652,3$ \\
$70 \%$ & 134,51 & 57.599 & 47.044 & $7.652,4$ \\
& & & 4 & \\
$50 \%$ & 115,01 & 49.248 & 47.038 & $7.652,5$ \\
\hline \hline
\end{tabular}

Pada grafik terlihat penurunan net power output seiring dengan menurunnya nilai Turbine Gas Load. Hal tersebut terjadi karena pada saat nilai Turbine Gas Load menurun, maka mass flow yang dihasilkan dari gas turbine akan menurun juga sesuai dengan data. Dengan berkurangnya mass flow exhaust gas maka pemanfaatan kalor yang terjadi pada HRSG kurang maksimal sehingga menyebabkan kurangnya produksi uap untuk memutar turbin uap.

\section{Gas Turbin Load VS Net Power Output}

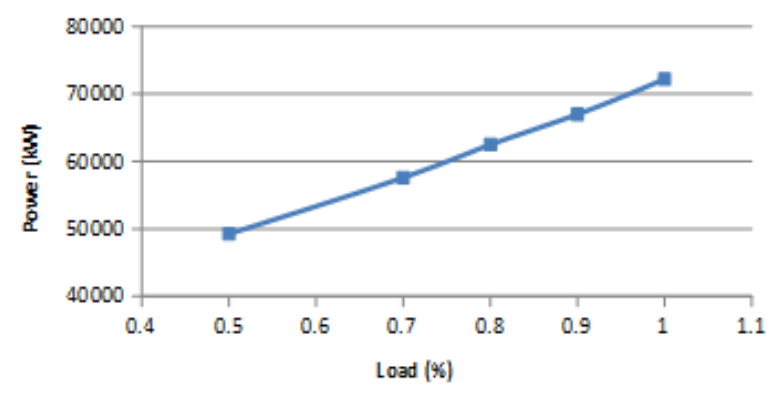

Gambar. 3. Grafik pengaruh Perubahan Beban Turbin Gas terhadap Net Power Output

\section{B. Variasi Pinch Point dan Approach Point}

Berdasarkan gambar 4 dapat dilihat hubungan antara perubahan pinch point dan approach point terhadap Power Output yang dihasilkan. Untuk pinch point, semakin kecil nilainya maka akan menghasilkan power output yang lebih tinggi. Begitu pula pada approach point. Hal tersebut dapat terjadi karena adanya peningkatan mass flow steam yang terbentuk ketika diberlakukan perubahan parameter dengan suplai kalor dari gas buang sama, sehingga dapat menghasilkan daya yang lebih besar juga.

Dengan meningkatnya daya yang dihasilkan, akan mengakibatkan terjadinya peningkatan efisiensi seperti ditunjukkan pada gambar 5. Hal tersebut dikarenakan untuk suplai kalor yang sama, ketika dilakukan penurunan nilai pada kedua parameter tersebut akan menghasilkan daya yang meningkat, sehingga efisiensi juga akan ikut meningkat. Kesesuaian hasil simulasi dengan teori yang ada dapat dihubungkan dengan mengaitkan ada persamaan (2), yang menyatakan bahwa dengan meningkatnya nilai daya yag dihasilkan maka akan membuat efisiensi ikut menigkat juga karena hubungan kedua nilai tesebut dalam persamaan adalah berbanding lurus. 
Power Output

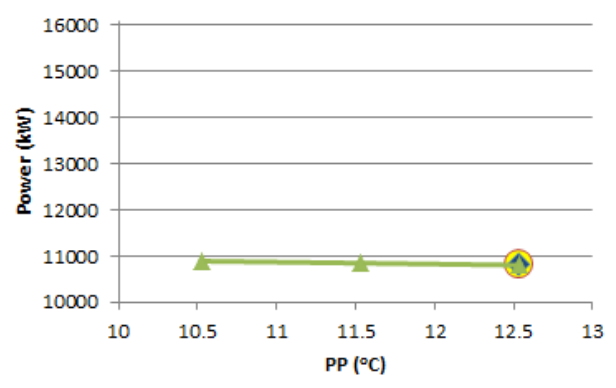

(a)

Power Output

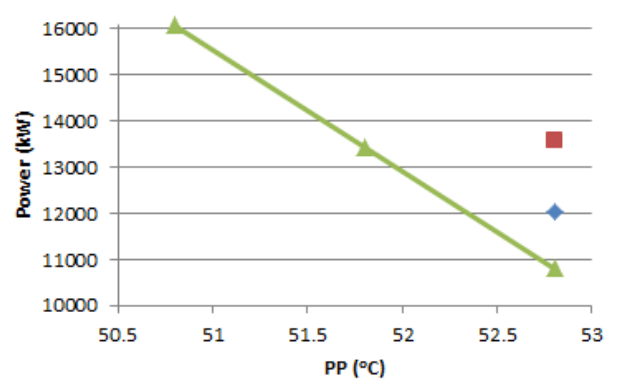

(b)

Gambar. 4. Grafik pengaruh Perubahan Pinch Point dan Approach Point terhadap Power Output (a) modul high pressure ; (b) modul low pressure

\section{Efficiency}

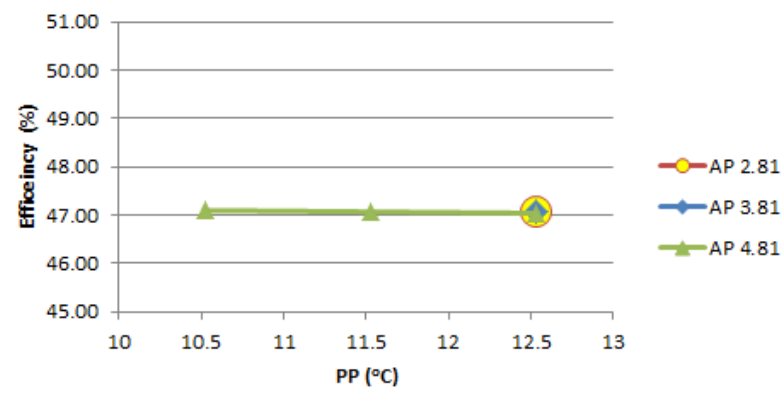

(a)

Efficiency

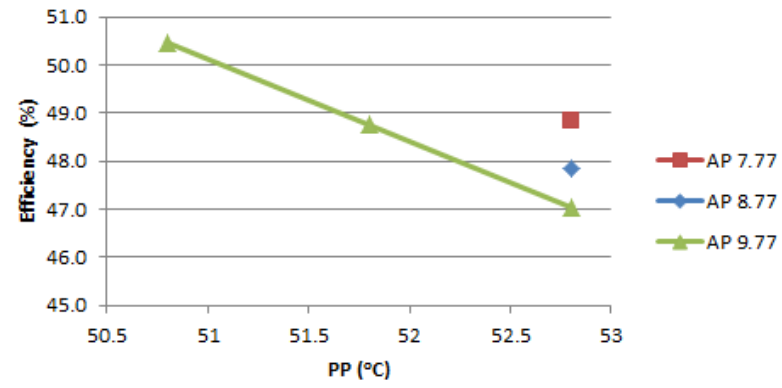

(b)

Gambar. 5. Grafik pengaruh Perubahan Pinch Point dan Approach Point terhadap Efisiensi (a) modul high pressure; (b) modul low pressure

Sementara itu, untuk nilai heat rate akan berlawanan terhadap pola yang dibentuk dari tren grafik daya, dan efisiensi. Dikarenakan, nilai daya menjadi pembagi dalam persamaan heat rate. Sehingga jika daya yang dihasilkan semakin besar, maka nilai heat rate-nya akan semakin kecil. Seperti yang ditunjukkan pada gambar 6 .
Heat Rate

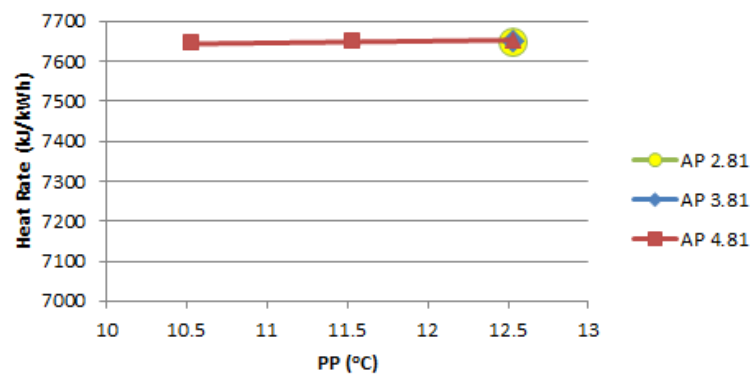

(a)

Heat Rate

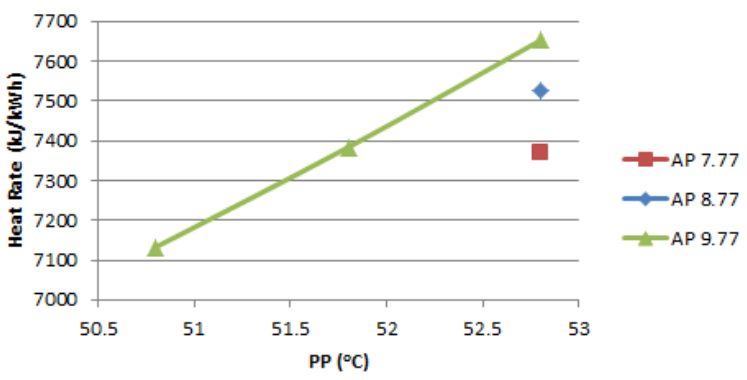

(b)

Gambar. 6. Grafik pengaruh Perubahan Pinch Point dan Approach Point terhadap Heat Rate (a) modul high pressure ; (b) modul low pressure

Jika melihat perbandingan massa yang dihasilkan dari modul high pressure dengan modul low pressure, terdapat perbedaan yang signifikan pada kenaikan massa yang dialami pada modul low pressure. Hal tersebut terjadi karena pada modul low pressure, uap yang dihasilkan akan difungsikan sebagai suplai deaerator. Sehingga jika terjadi peningkatan laju alir massa uap air dari low pressure evaporator, maka laju alir massa utama akan menyesuaikan peningkatan tersebut agar tidak terjadi proses evaporasi pada deaerator. Penyesuaian tersebut mengikuti azas Black, sehingga peningkatan laju alir massa uap air yang kecil dapat mengakibatkan peningkatan laju alir massa utama terlihat besar. Namun peningkatan laju alir massa yang besar tersebut tidak diimbangi dengan suplai energi panas yang besar, karena pada simulasi ini sumber panas hanya dikondisikan pada $100 \%$ beban turbin gas yang sesuai dengan data heat balance.

Contohnya pada kasus perubahan parameter pinch point pada modul LP HRSG yang menghasilkan daya terbesar sebesar $16 \mathrm{MW}$. Walaupun daya yang dihasilkan besar karena laju alir massa yang meningkat sangat besar pula, namun dapat dilihat pada gambar diatas bagian heat exchanger, total energy loss yang dimiliki siklus ini ternyata bernilai -25001 $\mathrm{kW}$, yang berarti untuk menghasilkan daya sebesar $16 \mathrm{MW}$ maka masih dibutuhkan sumber panas tambahan sebesar 25 MW. Sehingga sistem ini dinilai tidak optimal, karena sumber panas yang dibutuhkan harus ditambah seperti pengadaan duct burner. Dengan acuan sumber panas yang tetap maka sistem dengan pinch point $50,8^{\circ} \mathrm{C}$ pada modul low pressure tidak dapat diterapkan. Untuk itu perlu dilakukan optimalisasi agar tiap parameter bisa menghasilkan daya maksimum dengan sumber panas yang sudah disediakan. Tabel 3 dibawah adalah hasil simulasi untuk setiap parameter agar dihasilkan sistem optimal yang diupayakan memiliki energy loss mendekati $0 \mathrm{~kW}$, yang artinya semua panas yang diberikan gas buang akan diserap 
oleh sistem untuk membentuk uap air yang dibutuhkan untuk menghasilkan daya pada turbin uap.

Tabel 3.

Nilai Optimal Pada Parameter HRSG

\begin{tabular}{cccc}
\hline \hline & Nilai & Daya $(\mathbf{k W})$ & $\begin{array}{c}\text { Energy Loss } \\
(\mathbf{k W})\end{array}$ \\
\hline PP HP & 10,316 & 10902,16 & 0,01 \\
AP HP & 0,005 & 10897,76 & 21,61 \\
PP LP & 52,763 & 10902,81 & 3,71 \\
AP LP & 9,6902 & 10894,25 & 45,12 \\
\hline \hline
\end{tabular}

\section{KESIMPULAN}

Berdasarkan hasil simulasi pada software cycle tempo Pada pembangkit yang memanfaatkan heat recovery steam generator (HRSG) tekanan dua tingkat dengan turbin uap tekanan tunggal, dapat diambil beberapa kesimpulan sebagai berikut

1) Variasi perubahan beban turbin gas akan mempengaruhi proses pembangkitan uap pada HRSG yang mengakibatkan perubahan performa pada pembangkit secara keseluruhan. Penurunan beban turbin gas akan mengakibatkan menurunnya nilai total power. Namun pada kasus ini, untuk nilai net plant efficiency, dan net plant heat rate akan tetap, dikarenakan kondisi pembangkit menggunakan data $100 \%$ load sehingga tidak menunjukkan kondisi pada keadaan sebenarnya.

2) Semakin menurunnya nilai pinch point akan membuat pemindahan kalor menjadi semakin baik sehingga berakibat meningkatnya nilai total power, dan net plant efficiency, juga akan menurunnya nilai net plant heat rate.

3) Semakin menurunnya nilai approach point akan membuat mass flow steam menjadi lebih tinggi untuk perpindahan kalor yang tetap, sehingga berakibat meningkatnya nilai total power, dan net plant efficiency, juga akan menurunnya nilai net plant heat rate.

4) Hasil variasi parameter pada modul low pressure menunjukkan peningkatan laju alir massa yang signifikan, karena penyesuaian kesetimbangan laju alir massa pada deaerator dengan uap hasil evaporator.

\section{DAFTAR PUSTAKA}

[1] Moran, J. \& Howard N. Shapiro. Termodinamika Teknik Edisi 4. Jakarta: Erlangga. (2004)

[2] Ganapathy, V. Heat-Recovery Steam Generators: Understand the Basics. Texas: ABCO Industries. (1996)

[3] Arfandi, A. Analisis Full Repowering PLTU UNIT 1 PT PJB UP Gresik dengan Variasi Pinch Point pada Heat Recovery Steam Generator Menggunakan Software Cycle-Tempo. Surabaya: Institut Teknologi Sepuluh Nopember. (2016)

[4] A. Ragland, W. S. Combined Cycle Heat Recovery Optimization. Proceedings of 2000 International Joint Power Generation Conference, 1-6. (2000)

[5] Nugraha, D. Performansi Kolektor Surya Pemanas Air dengan Penambhan External Helical Fins pada Pipa dengan VAriasi Sudut Kemiringan Kolektor. Jurnal Teknik Pomits Vol. 4, No. 1. (2015) 